\title{
PENGEMBANGAN LEMBAR KERJA SISWA BERDASARKAN HASIL OBSERVASI KEANEKARAGAMAN MORFOLOGI TANAMAN MANGGA (Mangifera Indica)
}

\author{
Maryati $^{1 *}$, Ariefa Primairyani ${ }^{1}$, Sri Irawati ${ }^{1}$ \\ ${ }^{1}$ Program Studi Pendidikan Biologi, Fakultas Keguruan dan Ilmu Pendidikan, Universitas Bengkulu \\ Email : maymaymaryati2017@gmail.com
}

\begin{abstract}
ABSTRAK
Jenis penelitian ini adalah penelitian pengembangan. Penelitian ini bertujuan untuk mendeskripsikan keanekaragaman morfologi tanaman mangga (Mangifera indica) yang terdapat di kelurahan Padang Harapan Kota Bengkulu serta mendeskripsikan desain LKS hasil pengembangan berdasarkan observasi keanekaragaman morfologi tanaman mangga. Penelitian ini terdiri dari 6 tahapan yaitu 1) Tahap potensi dan masalah 2) Pengumpulan data 3) Desain produk 4) Validasi produk 5) Revisi produk 6) Uji keterbacaan LKS. Subjek penelitian ini adalah siswa/siswi kelas X IPA $\mathrm{S}_{5} \mathrm{SMAN} 01$ Kota Bengkulu. Teknik pengumpulan data pada penelitian adalah angket dan observasi. Hasil penelitian teridentifikasi 5 varietas tanaman mangga (Mangifera indica) yang digunakan sebagai bahan pembuatan LKS. Uji kelayakan LKS oleh ahli materi LKS mendapat persentase yaitu $78,8 \%$, oleh ahli bahan ajar (1) mendapat persentase yaitu $76,9 \%$, dan oleh ahli bahan ajar (2) mendapat persentase yaitu 84,6\% dengan rata-rata persentase secara keseluruhan yaitu 80,1\% dengan kategori layak. Hasil uji keterbacaan LKS oleh siswa secara keseluruhan menunjukkan persentase yaitu $87 \%$ dengan kategori sangat baik. Berdasarkan hasil validasi dan uji keterbacaan, dapat disimpulkan bahwa LKS yang dikembangkan layak dan memiliki kualitas baik.
\end{abstract}

Kata kunci: Pengembangan LKS, Tanaman mangga, Morfologi

\begin{abstract}
Type of the research is development research. This study aims to describe the morphological diversity of mango plants (Mangifera indica) in the urban villages of Padang Harapan of Bengkulu and describe the LKS design of the development based on the morphological observation of mango plants. This research consists of 6 stages: 1) Potential Stage and Problem 2) Data Collection 3) Product Design 4) Product Validation 5) Product Revision 6) Test of LKS legibility. The subject of this research is the students of grade X IPA 5 SMAN 01 Bengkulu city. Data completion technique in the research is questionnaire and observation. The results of the study identified 5 varieties of mango plants (Mangifera indica) used as material for making LKS. Feasibility test of LKS by LKS material experts got percentage that is $78,8 \%$, by expert of teaching material (1) got percentage that is $76,9 \%$, and by expert of teaching material (2) got percentage that is $84,6 \%$ with mean percentage overall that is $80.1 \%$ with a decent category. The results of LKS legality test by students as a whole showed the percentage of $87 \%$ with very good category. Based on the results of validation and legibility test, it can be concluded that LKS developed feasible and have good quality.
\end{abstract}

Keywords: Development Of LKS, Mango, Morphological 


\section{PENDAHULUAN}

Pendidikan memiliki peranan penting dalam suatu bangsa. Maju atau tidaknya suatu bangsa dapat dilihat dari kualitas pendidikan bangsa tersebut. Menurut Dimyati dan Mudjiono (2015), pendidikan merupakan suatu proses yang dirancang dan disusun secara sistematis untuk merangsang pertumbuhan, perkembangan, meningkatkan kemampuan dan keterampilan, kecerdasan, pembentukan watak, serta nilai dan sikap positif bagi setiap warga negara dalam rangka mencapai tujuan pendidikan. Untuk mencapai hal tersebut tentunya dibutuhkan suatu proses belajar mengajar yang merupakan kegiatan dalam melaksanakan kurikulum disuatu tempat lembaga pendidikan.

Pendidikan yang baik pun tak lepas dari suatu kurikulum yang dirancang dengan sedemikian rupa, agar dapat mencapai tujuan pendidikan itu sendiri secara sempurna. Kurikulum adalah seperangkat rencana dan pengaturan mengenai tujuan, isi dan bahan pelajaran serta cara yang di gunakan sebagai pedoman penyelenggaraan kegiatan pembelajaran untuk mencapai tujuan pendidikan tertentu. Kurikulum 2013 bertujuan untuk mempersiapkan manusia Indonesia agar memiliki kemampuan hidup sebagai pribadi dan warga Negara yang beriman, produktif, kreatif, inovatif, dan afektif serta mampu berkontribusi pada kehidupan bermasyarakat, berbangsa, bernegara, dan peradaban dunia (Permendikbud, 2014).

Berdasarkan hasil observasi awal yang telah dilakukan dengan guru di sekolah pada tanggal 18 Januari 2017, di dapatkan informasi bahwa penggunaan Lembar Kerja Siswa (LKS) inovasi yang dirancang sendiri oleh guru dalam pembelajaran biologi di sekolah belum dilakukan. Selain itu pembelajaran biologi yang dilakukan hanya berfokus kepada buku dan LKS yang dibeli oleh siswa dari penerbit. Menurut Damayanti
(2013), LKS yang digunakan oleh siswa dari penerbit sudah mengacu kepada enam unsur utama dalam bahan ajar LKS, namun dalam LKS tersebut masih terdapat banyak kekurangan seperti aktivitas belajar yang akan dilakukan oleh peserta didik tidak sesuai dengan kondisi sekolah kemudian tampilan gambar yang disajikan di dalam LKS pun tidak berwarna dan kurang spesifik sehingga tidak menarik minat belajar siswa. Hal ini yang membuat proses pembelajaran menjadi kurang efektif dan cenderung membosankan.

Menurut Prastowo (2011) Lembar Kerja Siswa (LKS) yaitu materi ajar yang sudah dikemas sedemikian rupa, sehingga peserta didik diharapkan dapat mempelajari materi ajar tersebut secara mandiri. Dalam LKS peserta didik akan mandapatkan materi, ringkasan, dan tugas yang berkaitan dengan materi. Selain itu peserta didik juga dapat menemukan arahan yang terstruktur untuk memahami materi yang diberikan.

Berdasarkan observasi awal, tanaman mangga cukup banyak dijumpai di kawasan kelurahan padang harapan kota Bengkulu. Jenis tanaman mangga yang dijumpai dikawasan padang harapan pada survey awal yang telah dilakukan seperti, mangga harum manis, mangga madu, mangga apel, dan mangga golek. Tanaman mangga (Mangifera indica) termasuk kedalam kelas magnoliopsida (tumbuhan dengan biji berkeping dua). Memiliki ciri-ciri yaitu sistem perakarannya tunggang, berdaun tunggal dengan bentuk lonjong, memiliki batang yang kuat, tegak, dan dapat tumbuh tinggi hingga 10 meter. Kulit batangnya tebal dan kasar. Bunganya termasuk kedalam tipe bunga majemuk. Buahnya termasuk kedalam kelompok buah batu berdaging, bentuk buahnya ada yang panjang, bulat dan pipih. Bijinya berkeping dua (dikotil). Tanaman mangga (Mangifera indica) ini merupakan salah satu tanaman yang banyak ditanam oleh masyarakat karena menghasilkan buah dengan cita rasa yang enak dan dapat memenuhi kebutuhan gizi manusia. Tanaman mangga ini memiliki banyak jenis dan 
varietasnya yang dapat kita amati secara karakteristik morfologinya.

Memberikan wawasan dan informasi bahwa semestinya pembelajaran biologi tidak terbatas hanya dengan membaca dan mengamati objek didalam buku. Akan tetapi, mengkaitkan pembelajaran dengan lingkungan sekitar. Misalnya dengan menggunakan bahan ajar berupa LKS yang dirancang sendiri oleh guru berdasarkan informasi yang didapatkan dari lingkungan sekitar sekolah terkait dengan materi pembelajaran yang akan disampaikan kepada siswa, sehingga menambah pemahaman siswa terhadap materi tersebut dan tercapai nya tujuan pembelajaran secara maksimal. Berdasarkan uraian tersebut, maka peneliti tertarik untuk meneliti keanekaragaman morfologi tanaman mangga (Mangifera indica) yang terdapat di Kelurahan Padang Harapan Kota Bengkulu, lalu mengemas hasil penelitian ke dalam bahan ajar berupa Lembar Kerja Siswa (LKS).

\section{METODE}

Jenis penelitian ini adalah penelitian dan pengembangan $(R \& D)$. Metode penelitian dan pengembangan ini menggunakan modifikasi langkah utama Borg \& Gall (1991) dalam Sugiyono (2008) yang terdiri atas a) Potensi dan masalah, b) Pengumpulan data, c) Desain produk, d) Validasi produk, e) Revisi produk, dan f) Uji keterbacaan.

Subyek penelitian pengembangan ini adalah siswa kelas X IPA 5 SMA Negeri 01 Kota Bengkulu tahun ajaran 2016/2017. Berjumlah 27 siswa dengan jumlah siswa laki-laki : 8 siswa dan jumlah perempuan : 19 siswa, serta obyek penelitian lainnya yaitu tanmaan mangga yang terdapat dikelurahan Padang Harapan kota Bengkulu.

Teknik pengumpulan data dengan cara observasi dan angket. Teknik pengumpulan data dengan cara observasi dilakukan untuk meneliti keanekaragaman morfologi tanaman mangga (Mangifera indica), sedangkan teknik pengumpulan data dengan angket digunakan untuk memvalidasi produk Lembar Kerja Siswa (LKS) yang telah dirancang oleh peneliti.

Teknik analisis data hasil pengamatan Mangifera indica di analisis menggunakan analisa deskriptif sedangkan, teknik analisis hasil validasi dari para validator yaitu 1 orang dosen Biologi dan 2 orang guru Biologi akan diubah menjadi data kuantitatif. Skor yang didapat dari masing-masing angket dihitung dengan menggunakan rumus dan disesuaikan dengan kategori penilaian ideal berikut

$$
P=\frac{\sum x}{\sum x i} X 100 \%
$$

Keterangan :

P : Persentase kevalidan

$\Sigma x \quad$ : jumlah jawaban responden per item

$\sum x i \quad$ jumlah nilai ideal per item

$100 \%$ : kostanta (Sulcha dkk, 2013)

Hasil analisis data yang berupa persentase tersebut kemudian dicocokkan dengan kriteria kevalidan yang dapat dilihat pada tabel 1.

Tabel 1. Kriteria kevalidan Lembar Kerja Siswa (LKS)

\begin{tabular}{ccl}
\hline $\begin{array}{c}\text { TINGKAT } \\
\text { PERSENTASE }\end{array}$ & KRITERIA & KETERANGAN \\
\hline $81,25 \%-100 \%$ & $\begin{array}{c}\text { Sangat } \\
\text { valid } \\
\text { Valid }\end{array}$ & $\begin{array}{l}\text { Layak/ tanpa } \\
\text { revisi } \\
\text { Layak/ dengan } \\
\text { revisi }\end{array}$ \\
$62,50 \%-81,24 \%$ & Kurang & $\begin{array}{l}\text { Kurang layak/ } \\
\text { revisi sebagian }\end{array}$ \\
$43,75 \%-62,49 \%$ & $\begin{array}{c}\text { valid } \\
\text { Sangat } \\
\text { kurang } \\
\text { valid }\end{array}$ & $\begin{array}{l}\text { Tidak layak/ } \\
\text { revisi total }\end{array}$ \\
& \\
& & \\
\hline
\end{tabular}

\section{HASIL DAN PEMBAHASAN}

Berdasarkan hasil penelitian yang telah dilakukan di kawasan kelurahan padang harapan kota Bengkulu ditemukan adanya 5 varietas dari tanaman mangga (Mangifera indica) yaitu dapat dilihat pada tabel dibawah ini :

$\begin{gathered}\text { Tabel 2. Varietas tanaman mangga (Mangifera } \\
\text { indica) di kelurahan Padang Harapan } \\
\text { kota Bengkulu }\end{gathered}$
\begin{tabular}{cc}
\hline No. & Varietas Mangga \\
\hline 1. & Mangga varietas harum manis \\
\hline
\end{tabular}



2. Mangga varietas golek
3. Mangga varietas apel
4. Mangga varietas madu
5. Mangga varietas Bengkulu

Berdasarkan observasi tanaman mangga (Mangifera indica) di Kelurahan Padang Harapan Kota Bengkulu diketahui bahwa terdapat banyaknya tanaman mangga yang ditemukan di lokasi penelitian, yaitu ada 5 varietas tanaman mangga yang teridentifikasi. Varietas tanaman mangga (Mangifera indica) yang teridentifikasi tersebut adalah mangga golek, harum manis, magga apel, mangga Bengkulu dan mangga madu. Mangifera indica merupakan tanaman yang termasuk ke dalam family anacardiaceae, dan termasuk kedalam genus Mangifera.

Pada umumnya secara fisik kelima tanaman mangga ini memiliki ciri-ciri yang hampir sama satu dengan yang lain, namun tetap ada beberapa ciri secara morfologi yang membedakan seperti dari bentuk buah, bentuk daun sampai dengan rasa yang dihasilkan dari buah tersebut. Mangga golek memiliki ciri buahnya yaitu bentuknya agak panjang sekitar $\pm 17 \mathrm{~cm}$ dan agak pipih, terdapat bintik-bintik putih dan tertutup lapisan putih tipis seperti lilin pada permukaan buahnya. Memiliki ketebalan kulit sedang, dengan daging buah yang tebal tidak berserat warna daging buah kuning tua. Mangga golek ini tidak memiliki paruh serta sinus yang tidak begitu terlihat jelas. Bentuk bijinya panjang pipih sekitar $\pm 14 \mathrm{~cm}$ dan terdapat serat pendek pada biji. Semua ciriciri mangga golek yang telah di jabarkan tersebut selaras dengan pernyataan dari Pracaya (2001) yang mengatakan bahwa mangga golek memiliki kulit buah dengan ketebalan sedang, ada selaput lilin tipis yang menutupi permukaan buah dan ada bintikbintik kelenjar berwarna putih kehijauan yang bila tua bintik tersebut akan berubah warna menjadi putih kecoklatan.
Tanaman mangga harum manis memiliki bentuk buah yang tidak terlalu panjang dan juga tidak terlalu bulat dengan sinus dan paruh yang terlihat jelas, serta permukaan buah tertutupi dengan lapisan lilin. Selaras dengan pernyataan dari Pracaya (2001) yang mengatakan bahwa mangga harum manis memiliki bentuk bulat panjang dengan paruh dan sinus (lekukan) jelas terlihat. Hampir sama dengan mangga golek, mangga harum manis juga memiliki kulit buah yang tidak begitu tebal dan terdapat kelenjar bintik-bintik putih pada permukaannya. Daging buahnya tebal, berwarna kuning dan tidak berserat, memiliki aroma wangi yang kuat dan rasa yang manis.

Selanjutnya mangga madu menurut Pracaya (2001) buahny memiliki ciri bentuk bulat panjang, pangkal dan ujung buah bulat, kulit buah halus terdapat lapisan lilin dan bintik-bintik kelenjar berwarna putih kehijauan. Warna daging buah ketika masak berwarna kuning dengan bagian tengah didalam daging buah di dekat biji berwarna lebih oren (kuning gelap) seperti warna madu. $\mathrm{Hal}$ ini sesuai dengan hasil pengamatan yang telah dilakukan dimana memang terdapat bagian yang berwarna lebih kuning gelap seperti warna madu pada bagian dalam daging buah mangga madu tersebut. Buah mangga madu ini juga memiliki aroma yang wangi dan rasa yang sangat manis layaknya madu.

Tanaman mangga apel memiliki bentuk buah bulat, tidak memiliki sinus dan paruh bentuk buahnya seperti bentuk buah apel, dengan terdapat cekungan pada pangkal buahnya. Permukaan buahnya tidak begitu licin dan berwarna kehijauan serta terdapat bintik-bintik kelenjar putih. Pada saat telah matang permukaan kulit berwarna kuning kemerahan. Tekstur daging buah matang yaitu halus tidak berserat, serta berwarna kuning keorenan. Memiliki biji yang berbentuk bulat pipih berukuran $5-6 \mathrm{~cm}$ dengan serat pendek. Hal ini sesuai menurut Salatin (2012) bahwa varietas mangga apel ini memiliki permukaan kulit yang tipis, berwarna 
kuning kemerahan pada saat matang. Memiliki tekstur daging buah yang halus, dengan aroma yang harum dan memiliki rasa yang manis.

Tanaman mangga Bengkulu memiliki bentuk buah yang lonjong panjang dengan ukuran yang besar. Memiliki sinus terlihat jelas, sedikit berparuh. Permukaan kulit buah saat matang berwarna hijau kekuningan. Daging buahnya berwarna kuning dan tidak berserat. Memiliki tekstur daging buah lunak dengan aroma yang harum namun tidak terlalu kuat, serta memiliki rasa daging buah yang manis dengan sedikit asam. Mangga Bengkulu ini memiliki biji dengan bentuk panjang pipih sekitar $18 \mathrm{~cm}$. Ciri-ciri dari tanaman mangga Bengkulu yang telah di amati oleh peneliti selaras dengan apa yang sudah tercantum di dalam SK Menteri Pertanian nomor. 337 tahun 2003, bahwa tanaman mangga Bengkulu ini memiliki ciri
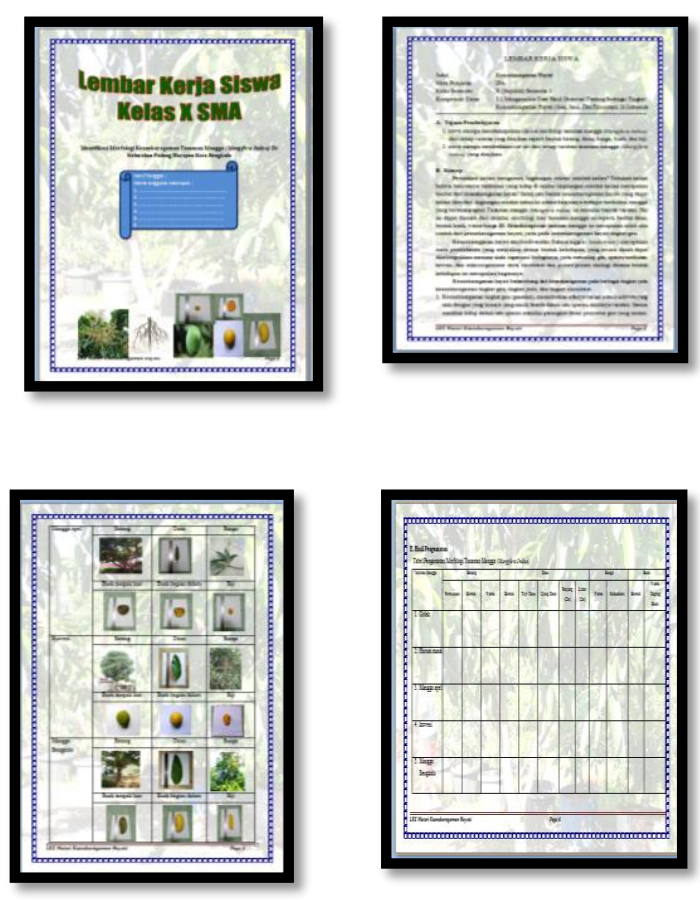

yaitu memiliki bentuk buah bulat agak lonjong sedikit berparuh, berkulit tipis dengan warna kulit hijau kekuningan saat matang. Tekstur daging buahnya lunak berserat halus serta berwarna kuning. Memiliki rasa manis sedikit asam dengan aroma buah sedang. Memiliki bentuk biji yang panjang dan pipih.

Hasil penelitian yang dilakukan berdasarkan observasi tanaman mangga (Mangifera indica) di kelurahan Padang Harapan Kota Bengkulu dikembangkan menjadi bahan ajar berupa Lembar Kerja Siswa (LKS). Pengembangan yang dilakukan pada LKS ini meliputi aspek desain, tujuan pembelajaran, materi, kegiatan dan pertanyaan. Desain LKS yang di uji cobakan pada pembelajaran Biologi materi keanekeragaman hayati, setelah melalui tahap revisi terdiri dari 8 halaman yaitu sebagai berikut :
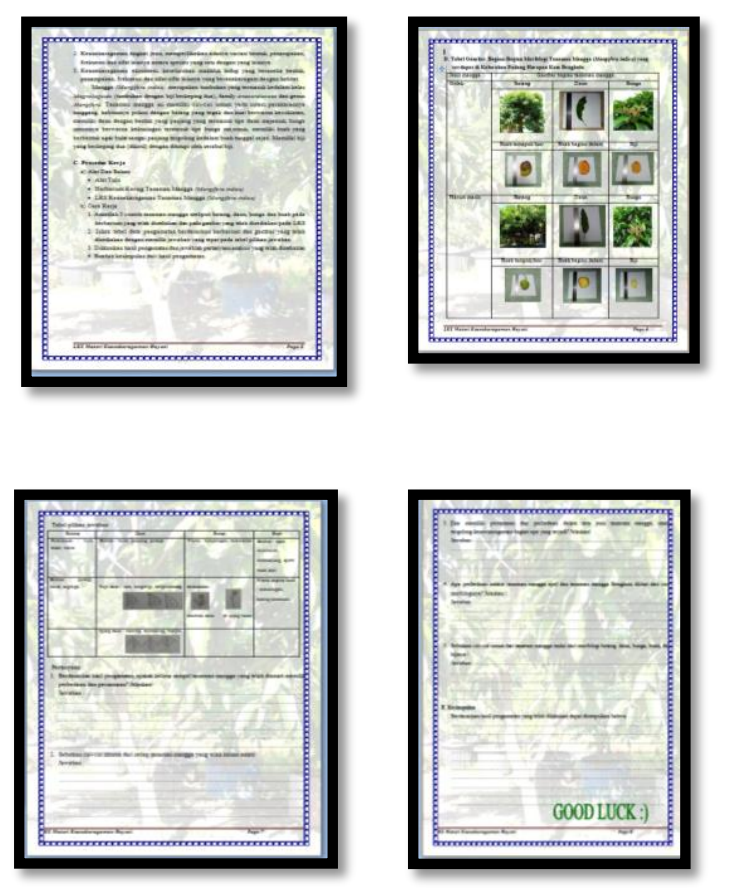

Gambar 1. Desain Rancangan LKS

Pengembangan desain LKS dimulai dari penyusunan LKS dengan model reconstruction atau rekontruksi. Menurut Devi dkk (2009) LKS model rekontruksi memiliki kegiatan seperti melengkapi suatu tabel berdasarkan data yang diperoleh, baik dari pengamatan langsung atau grafik. Pembelajaran menggunakan LKS membantu siswa untuk mengkonstruksi pengetahuan ke dalam 
otak mereka melalui tahapan berpikir, yaitu mengamati, menganalisis kemudian menyimpulkan. Kegiatan mengamati karakter morfologi dari contoh tanaman mangga yang didapat dari hasil observasi merupakan usaha untuk membuat materi lebih bersifat konkret. Selain itu, dibantu juga dengan pertanyaan analisis untuk mendorong siswa agar mampu menemukan konsep keanekargaman hayati tingkat gen dari pengamatan variasi warna bunga dan bentuk buah mangga.

Aspek yang dikembangkan pada LKS ini meliputi desain, tujuan pembelajaran, materi, kegiatan siswa, dan pertanyaan. Desain LKS dirancang dengan mengunakan kertas ukuran A4 (kuarto), kepadatan halaman yang rendah dan penomoran yang jelas serta susunan yang sistematis. Prastowo (2011) menyimpulkan LKS yang memiliki desain sulit dan rumit bagi siswa, maka mereka akan kesulitan memahami materi. Tujuan pembelajaran pada lembar kerja siswa disesuaikan dengan kompetensi dasar 3.2 agar siswa mampu melakukan kegiatan pengamatan, menjelaskan ciri-ciri setiap contoh tanaman mangga dan konsep keanekaragaman hayati tingkat gen.

Lembar Kerja Siswa (LKS) yang telah selesai dikembangkan peneliti terlebih dahulu divalidasi oleh 1 Dosen Pendidikan Biologi dan 2 Guru Biologi SMAN 1 kota Bengkulu. Apabila sudah diketahui kelemahan dalam LKS maka akan diperbaiki/revisi sebelum diuji cobakan dalam pembelajaran. LKS yang akan dikembangkan tersebut telah memiliki validitas yang logis dan dapat diimplementasikan pada pembelajaran Biologi SMA dengan materi keanekaragaman hayati di kelas $\mathrm{X}_{\mathrm{IPA}_{5}}$ SMAN 1 kota Bengkulu. Hasil validasi dan saran validator dapat dilihat pada Tabel 3.

Berdasarkan validasi yang telah dilakukan oleh 1 dosen pendidikan biologi dan 2 guru biologi SMAN 1 kota Bengkulu didapatkan hasil bahwa rerata skor yang di dapat yaitu $80,1 \%$ semuanya dalam katergori "Valid/Baik". Kriteria LKS yang diperoleh dari masing-masing ahli yaitu layak dengan revisi sebelum dilakukan uji lapangan. Menurut Widarmayanti dkk (2015) yang diharapkan dari validasi adalah masukan perbaikan LKS. Saran yang diberikan oleh validator adalah acuan untuk perbaikan produk LKS tersebut agar sesuai dengan aspek-aspek pembelajaran, seperti tujuan pembelajaran, kegiatan LKS, tampilan LKS dan pertanyaan analisis.

Tabel 3. Respon Validator Terhadap LKS Keanekaragaman Hayati Tanaman Mangga (Mangifera indica)

\begin{tabular}{cccclc}
\hline No. & Validator & $\begin{array}{c}\text { Aspek } \\
\text { Yang } \\
\text { Diamati }\end{array}$ & Kriteria & Saran Perbaikan & Persentase \\
\hline 1. & $\begin{array}{c}\text { Dosen } \\
\text { pendidikan } \\
\text { biologi (IA) }\end{array}$ & $\begin{array}{c}\text { Materi } \\
\text { dan } \\
\text { bahasa }\end{array}$ & $\begin{array}{c}\text { Layak } \\
\text { dengan } \\
\text { revisi }\end{array}$ & $\begin{array}{l}\text { Perlu diperhatikan herbarium } \\
\text { buah dan bunga yang } \\
\text { digunakan, apakah tidak } \\
\text { sebaiknya menggunakan } \\
\text { buah dan bunga yang segar }\end{array}$ & $78,8 \%$ \\
2. & $\begin{array}{c}\text { Gurubiologi 1 } \\
\text { (DH) }\end{array}$ & $\begin{array}{c}\text { Bahan } \\
\text { ajar }\end{array}$ & $\begin{array}{c}\text { Layak } \\
\text { dengan } \\
\text { revisi }\end{array}$ & $\begin{array}{l}\text { Sebaiknya tabel gambar } \\
\text { tanam manga dan soal } \\
\text { pertanyan dibuat dengan } \\
\text { posisi portrait saja agar lebih } \\
\text { efisien }\end{array}$ & 76,9\% \\
\hline
\end{tabular}




\begin{tabular}{|c|c|c|c|c|c|}
\hline & & & & $\begin{array}{l}\text { Komentar setelah dilakukan } \\
\text { revisi yaitu sudah lebih bagus } \\
\text { dan efektif setelah direvisi }\end{array}$ & \\
\hline \multirow[t]{2}{*}{3.} & $\begin{array}{c}\text { Guru biologi } 2 \\
\text { (S) }\end{array}$ & $\begin{array}{c}\text { Bahan } \\
\text { ajar }\end{array}$ & $\begin{array}{l}\text { Layak } \\
\text { dengan } \\
\text { revisi }\end{array}$ & $\begin{array}{l}\text { Beberapa gambar yang } \\
\text { disajikan ada yang kurang } \\
\text { jelas sebaiknya diperbaiki } \\
\text { Komentar setelah dilakukan } \\
\text { revisi yaitu gambar yang } \\
\text { disajikan sudah lebih jelas }\end{array}$ & $84,6 \%$ \\
\hline & $\begin{array}{l}\text { Rata-rata } \\
\text { Kriteria : Valid }\end{array}$ & & & & $80,1 \%$ \\
\hline
\end{tabular}

Kriteria LKS yang direspon oleh siswa mendapatkan hasil yang "sangat baik" dengan persentase nilai sebesar $87 \%$. Hasil analisis menunjukkan bahwa tidak semua kriteria mendapatkan respon yang baik seperti pada pernyataan angket nomor 5 dan 8 yang mendapatkankan persentase respon di bawah $80 \%$ sedangkan yang lainya mendapatkan persentase respon diatas $80 \%$. Salah satu komentar dan saran siswa mengenai LKS seperti, LKS yang digunakan sudah bagus dalam bentuk materi, dan mudah untuk dipahami. Hasil analisis angket respon siswa terhadap LKS dapat dilihat pada Tabel 4.

Tabel 4. Rekapitulasi Hasil Respon Siswa Terhadap LKS

\begin{tabular}{|c|c|c|c|c|c|}
\hline \multirow{3}{*}{ No } & \multirow{3}{*}{ Pertanyaan angket } & \multicolumn{4}{|c|}{ Hasil Respon } \\
\hline & & \multicolumn{2}{|c|}{ Ya } & \multicolumn{2}{|c|}{ Tidak } \\
\hline & & $\Sigma$ & $\%$ & $\sum$ & $\%$ \\
\hline 1. & Apakah susunan kalimat pada LKS mudah dipahami ? & 26 & $96 \%$ & 1 & $4 \%$ \\
\hline 2. & $\begin{array}{l}\text { Apakah petunjuk dan prosedur kerja dari LKS ini sudah jelas } \\
\text { ? }\end{array}$ & 24 & $89 \%$ & 3 & $11 \%$ \\
\hline 3. & $\begin{array}{l}\text { Apakah anda senang selama mengikuti pembelajaran } \\
\text { menggunakan LKS dari hasil penelitian tanaman mangga? }\end{array}$ & 25 & $92 \%$ & 2 & $7 \%$ \\
\hline 4. & Apakah tampilan LKS ini menarik? & 23 & $85 \%$ & 4 & $14 \%$ \\
\hline 5. & $\begin{array}{l}\text { Apakah anda lebih memahami materi keanekeragaman gen } \\
\text { setelah membaca LKS hasil penelitian ini ? }\end{array}$ & 21 & $75 \%$ & 6 & $22 \%$ \\
\hline 6. & $\begin{array}{l}\text { Apakah contoh tanaman mangga yang diberikan di LKS } \\
\text { sudah cocok dengan keanekaragaman gen? }\end{array}$ & 26 & $96 \%$ & 1 & $4 \%$ \\
\hline 7. & $\begin{array}{l}\text { Apakah anda dilatih untuk melakukan kegiatan mengamati, } \\
\text { mengukur, dan menggolongkan? }\end{array}$ & 27 & $100 \%$ & - & - \\
\hline 8. & $\begin{array}{l}\text { Apakah LKS ini, dapat melatih anda untuk menarik } \\
\text { kesimpulan dari hasil kegiatan pembelajaran? }\end{array}$ & 19 & $70 \%$ & 8 & $30 \%$ \\
\hline & $\begin{array}{c}\text { Jumlah rerata persentase } \\
\text { kategori }\end{array}$ & & $\begin{array}{r}87 \\
\text { Sanga }\end{array}$ & & \\
\hline
\end{tabular}

\section{PENUTUP}

\section{Simpulan}

1. Berdasarkan hasil observasi keanekaragaman morfologi tanaman mangga (Mangifera indica) di Kelurahan Padang Harapan Kota Bengkulu di dapatkan ada 5 varietas dari tanaman mangga yang di jumpai di lokasi yaitu mangga var.golek, mangga var.harum manis, mangga var.apel, mangga var.madu, dan mangga var.Bengkulu.

2. Lembar kerja siswa (LKS) yang dirancang berdasarkan dari penelitian morfologi tanaman mangga (Mangifera indica) 
"layak" digunakan dalam pembelajaran biologi pada materi keanekaragaman hayati yang dibuktikan dengan hasil validasi yang telah dilakukan oleh validator dengan persentase nilai ratarata yaitu $80,1 \%$ serta respon siswa kelas X SMAN 01 kota Bengkulu terhadap LKS "sangat baik" yang dibuktikan dengan hasil persentase nilai rata-rata yaitu $87 \%$.

\section{Saran}

1. Perlu dilakukannya penelitian lebih lanjut mengenai morfologi tanaman mangga (Mangifera indica) ini pada lokasi yang berbeda agar dapat dilihat adanya perbandingan antara satu lokasi dengan lokasi yang lain.

2. Produk LKS hasil penelitian tanaman mangga (Mangifera indica) dapat dikembangkan lagi menjadi lebih baik dan dapat diuji cobakan dalam proses pembelajaran.

\section{DAFTAR PUSTAKA}

Damayanti, E.K. 2013. Pengelolaan Keanekaragaman hayati Tumbuhan Obat dan Tumbuhan Berguna. Departemen Konservasi Sumberdaya Hutan dan Ekowisata Fakultas Kehutanan IPB

Dimyati dan Mudjiono. 2015. Belajar dan Pembelajaran. Jakarta : PT Rineka Cipta

Devi, Poppy Kamala., Soefiraeni Renny., dan Khaituddin. 2009. Pengembangan Perangkat Pembelajaran. Jakarta : PTK IPA.

Permendikbud. 2014. Peraturan Menteri Pendidikan Dan Kebudayaan Republik Indonesia Nomor 58 Tahun 2014 Tentang Kurikulum 2013 Sekolah Menengah
Pertama/ Madrasah Tsanawiyah. Jakarta: Depdiknas

Prastowo, Andi. 2011. Panduan Kreatif Membuat Bahan Ajar Inovatif. Yogyakarta: Diva Press.

Pracaya. 2001. Bertanam Mangga. Jakarta:Penebar swadaya.

Sulcha, Amalia Rif"atus., Sri Endah Indriwati., dan Murni Saptasari. 2013. Pengembangan Lembar Kerja Siswa (Lks) Biologi Berbasis Inkuiri Untuk Membangun Keterampilan Proses Siswa Sma Negeri 5 Malang Kelas X Semester Genap Materi Ekosistem. jurnalonline.um.ac.id.

http://www.google.com (Diakses pada tanggal 22 Januari 2017).

Salatin, Nurjanah Puspa. 2012.Perbanyakan tanaman mangga (Mangifera indica) dengan cara cangkok di UPTD B2TPH, Tohudan Colomadu Karanganyar.

http://digilib.uns.ac.id (di akses pada tanggal 5 februari 2018 pukul 11.00)

Surat Keputusan Menteri Pertanian Nomor.337/Kpts/Tp.240/6/2003

Sugiyono. 2008. Metode Penelitian Kuantitatif dan Kualitatif. Bandung: Penerbit Alfabet

Widarmayanti, R. P., Susantini, E., dan Ambarwati, R. 2015. Profil Validitas LKS Berbasis Keterampilan Proses Pada Subpokok Bahasan Invertebrata Untuk Kelas X SMA. Jurnal Bioedu Vol.4 No.1 Januari 2015 ISSN: 2302-9528. Surabaya: Jurusan Pendidikan Biologi FMIPA Universitas Negeri Surabaya 